Article

\title{
The Effect of Social Undermining on Employees' Emotional Exhaustion and Procrastination Behavior in Deluxe Hotels: Moderating Role of Positive Psychological Capital
}

\author{
Hyo-Sun Jung $1, *,+$ (i) and Hye-Hyun Yoon ${ }^{2,+}$ \\ 1 Center for Converging Humanities, Kyung Hee University, Seoul 02447, Korea \\ 2 Department of Culinary Arts and Food Service Management, Kyung Hee University, Seoul 02447, Korea; \\ hhyun@khu.ac.kr \\ * Correspondence: chefcook@khu.ac.kr \\ + These authors contributed equally to this work.
}

Citation: Jung, H.-S.; Yoon, H.-H. The Effect of Social Undermining on Employees' Emotional Exhaustion and Procrastination Behavior in Deluxe Hotels: Moderating Role of Positive Psychological Capital. Sustainability 2022, 14, 931. https:// doi.org/10.3390/su14020931

Academic Editor: Andrea Pérez

Received: 13 December 2021

Accepted: 10 January 2022

Published: 14 January 2022

Publisher's Note: MDPI stays neutral with regard to jurisdictional claims in published maps and institutional affiliations.

Copyright: (C) 2022 by the authors. Licensee MDPI, Basel, Switzerland. This article is an open access article distributed under the terms and conditions of the Creative Commons Attribution (CC BY) license (https:// creativecommons.org/licenses/by/ $4.0 /)$.

\begin{abstract}
The purpose of this study was to determine if social undermining as perceived by frontline employees significantly affects their emotional exhaustion and procrastination behavior and to clarify the moderating role of positive psychological capital. A total of 310 deluxe hotel employees in South Korea participated in this study by completing a self-administered questionnaire. The study results showed that social undermining perceived by deluxe hotel employees positively influenced their emotional exhaustion. In addition, when emotional exhaustion became severe, employees' procrastination behavior, which harmed their organizations, increased. Additionally, the findings suggest a mediating effect, thereby indicating that employees' procrastination behaviors may increase when they experience emotional exhaustion resulting from social undermining. When employees perform their jobs with a positive attitude in a work situation, the negative influence of social undermining and emotional exhaustion may be partially offset. Limitations and future research directions are also discussed.
\end{abstract}

Keywords: social undermining; emotional exhaustion; procrastination behavior; positive psychological capital; deluxe hotel

\section{Introduction}

Individuals' healthy and supportive relationships with those they encounter in an organization are a highly important resource for their happiness and performance [1,2]. From an organizational perspective, smooth interpersonal relationships are essential to its efficient and effective functioning [3]. Individuals' failure to form positive relationships with others in a social group, such as an organization, leads to their decreased organizational performance. Social undermining is an offense committed by an individual that intentionally diminishes another's good reputation and obstructs positive relationships with others in an organization [4]. Hence, social undermining can be viewed as a type of interpersonal relationship abuse [5]. Social undermining causes interpersonal relationship behavior that can damage social capital [6,7], ultimately incurring social costs [8]. Damage due to social undermining by an individual is initially minor, but can become a serious problem when an employee advances their own position through actions, such as continuous underestimation, slander, non-disclosure of information, ignorance, and intentional silence, that adversely affect others [9]. The victims' resulting perception of a negative social environment triggers their conflictive social interactions, which results in an undesirable outcome for the assailant as well as the organization as a whole [3,10-12].

Deluxe hotels specifically provide a wide range of special services to customers. Their employees perform tasks that place them in close relationships with their superiors, coworkers, and customers. Mathisen et al. [13] asserted that disadvantageous and poor working 
conditions aggravated negative emotions among employees, making them overlook and take social undermining for granted, and they found that such social undermining had a high possibility of taking place in a hierarchical organizational culture [14]. Such a situation corresponds closely with the culture and organizational characteristics of hotels. Nonetheless, there has been no research that has investigated social undermining in deluxe hotels. In addition, employees' procrastination behaviors are highly expensive to an organization [15]. Ferrari et al. [16] and Sirois [17] noted that procrastination behaviors ordinarily accompanied employees' stress, psychological discomfort, and poor health conditions, and therefore resulted in the organization's negative performance. Sharma and Gupta [18] observed that $50 \%$ of the time used surfing on the Internet during working hours was unrelated to the job. In addition, our study will be able to provide substantial results, as employees at five-star hotels comprise a typical occupational group that performs emotional labor and emotional exhaustion is their most significant stress factor [19] and the organizational climate can be changed through positive psychological capital [20]. Positive psychological capital, which refers to psychological conditions experienced in working circumstances, is highly important because it can change depending on the organizational climate, rather than being fixed as a personal characteristic [21]. Therefore, the purpose of this study was as follows: (1) to examine the influence of social undermining on emotional exhaustion and procrastination behavior; (2) to verify the influence of emotional exhaustion on procrastination behavior; (3) to clarify the mediating effect of emotional exhaustion on social undermining and procrastination behavior; (4) to investigate the moderating effect role of positive psychology capital. Through this study, awareness of the importance of social undermining that occurs in the socialization process of organization can be increased. Investigations into the negative influence of social undermining will provide an opportunity to discuss responsive measures at an organizational level.

\section{Literature Review and Conceptual Model}

\subsection{Theoretical Framework}

A study proved that social undermining is in a close relationship with negative behavior based on the social cognitive theory [22], arguing that learning takes place through interaction among personal factors, environmental events, and behaviors. Social undermining negatively affects individuals' social relationships and their success [9] and refers to intentional behaviors to continuously impede individuals' efforts to have positive interpersonal relationships and to develop a favorable reputation [4]. Sassali [23] defined emotional exhaustion as a state in which energy is exhausted due to the continuous frustration of individual desires. Montgomery et al. [24] defined emotional exhaustion as decreased job performance ability resulting from exhaustion of physical, emotional, and mental energy [25]. Procrastination behavior means procrastinating work for unnecessary and unreasonable purposes in a job situation [26]. PPC is an organizational member's positive psychological state and considers an individual's psychological state in a job situation, not their characteristic disposition [21]. In addition, we tried to verify if the negative impact of social undermining can be recovered through positive psychological capital through resource conservation theory [27-29]. In this study, we intended to explore the effects of social undermining on emotional exhaustion and procrastination behavior using these variables and examine the moderating role of PPC (Figure 1).

\subsection{Relationships among Social Undermining and Emotional Exhaustion}

Several studies have focused on social undermining and its positive relationship with employees' emotional exhaustion (see hypothesis below). Grant et al. [30] suggested that social undermining made social welfare workers hypersensitive and increased their emotional exhaustion, triggering depression or anxiety. Additionally, Andersson and Pearson [31] stated that behaviors by individuals' coworkers, customers, and superiors that weakened and intimidated these individuals provided motivation for the victim to retaliate with similar behavior by responding adversely to such negative behavior, thereby 
triggering serious conflicts in the workplace. Bakker et al. [32] observed that social undermining perceived by employees in their socialization process had a significant positive correlation with their emotional exhaustion. In addition, Strongman [33] found that social undermining aggravated individuals' psychological pain and emotional exhaustion, whereas social support increased their emotional health. Rahimnia et al. [34] determined that social undermining experienced by nurses in their work environment increased their burnout and that decreasing the elements of social undermining may weaken their burnout. Furthermore, Sârbescu et al. [2] asserted that social undermining committed by supervisors increased employees' burnout and that their experience of social undermining was closely related with their emotional exhaustion [35]. In a similar context, Kalliath and Beck [36] argued that supervisors' insufficient support and their lack of assistance were major factors for increasing employees' burnout, and Muhammad and Hamdy [37] observed that employees' emotional exhaustion decreased when they perceived they were receiving support from their superiors. Charoensukmongkol et al. [38] found that collaboration with coworkers and supervisors and their support reduced employees' emotional exhaustion. In addition, Meier and Cho [39] cited that social undermining among colleagues increased psychological separation. Cho et al. [40], Prof and Yagil [41], and Silter et al. [42] asserted that employees' emotional exhaustion rapidly increased when they were subject to social incivility or unjust treatment by customers. Based on these integrated results of previous studies, we opined that employees' increased experience with social undermining in their organizations would lead to their increased emotional exhaustion.

Hypothesis 1. Social undermining has a positive relationship with emotional exhaustion.

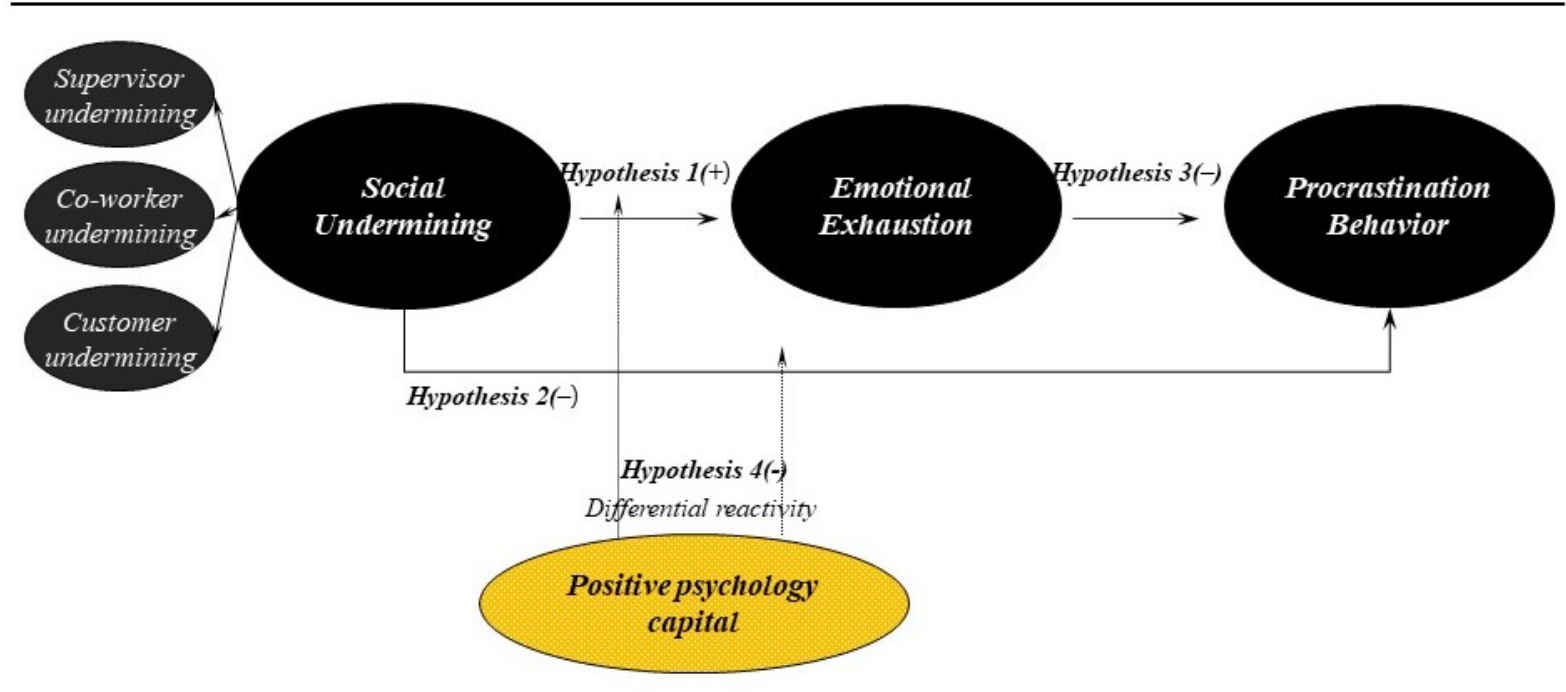

Note: (1) Solid lines are main effects and dotted lines are moderating effects; (2) Control variables: Gender, Age, Education (Time 1)

Figure 1. Research model and hypotheses of the relationships between social undermining, emotional exhaustion, procrastination behavior, and positive psychological capital.

\subsection{Relationships among Social Undermining, and Procrastination Behavior}

No previous study examined the relationship between social undermining and procrastination behaviors. Nonetheless, the following studies examined the association between social undermining and employees' negative behaviors under the assumption that employees' procrastination behaviors are negative behaviors that harm an organization. Duffy et al. [4] noted that social undermining encouraged counterproductive behaviors in employees. Duffy et al. [43] asserted that a high level of undermining in a social context increased the possibility for employees to harm to their organizations and that there was a 
close correlation between social undermining and counterproductive worker behaviors. Lee and Spector [44] found that disputes with supervisors and coworkers encouraged counterproductive behaviors by employees. Crossley [14] observed that social undermining committed by supervisors or coworkers may provoke avoidance behaviors or retaliation against an unidentified member(s) of the general public. Duffy et al. [9] suggested that frequently occurring social undermining leads to employees' moral deviation. Yoo [45] argued that a person believes that they are not appropriate for certain work when they become aware of social undermining from boss and colleagues; the possibility of conducting actions harmful to the organization and customers increases in this case. On the contrary, low awareness of social undermining can make the member not only fulfill their own role but also conduct behaviors that benefit the organization. Ong and Tay [46] asserted that social undermining by coworkers decreased the positive effect of the employees' organizational citizenship behaviors. In a similar context, Sabeen and Arshad [47] noted that social undermining has a direct impact on psychological and overall wellbeing. Furthermore, it affects work performance and eventually causes negative behaviors, such as withdrawal or drop out from voluntary action. Consequently, the social undermining experienced by employees will reduce the possibility that they behave positively for their organizations.

\section{Hypothesis 2. Social undermining has a positive relationship with procrastination behavior.}

\subsection{Relationships between Emotional Exhaustion and Procrastination Behavior}

Studies have shown a positive relationship between employees' emotional exhaustion and procrastination behavior, Liang and Hsieh [48] observed that emotional exhaustion experienced by employees in their organizations significantly increased counterproductive behaviors that were harmful to their organizations. Krischer et al. [49] said that employees with emotional exhaustion were highly likely to execute counterproductive work behaviors. Additionally, Cropanzano et al. [50] and Van Jaarsveld et al. [51] determined that employees' emotional exhaustion is a type of chronic exhaustion that positively influences employees' deviant behaviors because such undermining is detrimental to their ability to properly maintain their job-related behaviors and to inhibit inadequate job-related behaviors. Furthermore, Çelik et al. [52] noted that when employees experienced exhaustion in a job situation, they were likely to act aberrantly in interpersonal relationships. In a study of students, Balkis [53] observed that their exhaustion and intentional academic procrastination had a very close correlation. Ugwu et al. [54] found that, compared to those with a low level of exhaustion, employees with a high level of exhaustion were likely to intentionally use counterproductive behaviors harmful to their organization. Given these findings, a third hypothesis was developed:

Hypothesis 3. Employees' emotional exhaustion has a positive relationship with procrastination behavior.

\subsection{Moderating Role of Employees' Positive Psychological Capital (PPC)}

No research has examined PPC as a moderating variable that alleviates the negative influence of social undermining in employees' socialization process in an organization. However, Luthans et al. [21] emphasized the effectiveness of employees' positive psychology, noting that employees' PPC affected an organization's supportive climate. In addition, employees' PPC increased their positive behaviors and decreased their negative behaviors within an organization [55]. Lee and Choi [56] reported that PPC boosted employees' positive psychological state and motivational process, thereby increasing their degree of satisfaction with their job and significantly affecting their perceived performance. George and Brief [57] found that employees' positive psychology or experiences were directly related to their willingness to help their coworkers or superiors. In a study of variables that may moderate the negative influence of social undermining, Rahimnia et al. [34] noted that self-esteem decreased the influence of social undermining on burnout and that 
high self-esteem may offset the negative influence of social undermining. In addition, Grant et al. [27] explained that the negative influence of social undermining on burnout was reduced when employees perceived that they were receiving social support. Yoo [45] argued that the effect of social undermining perceived by employees on their negative performance decreased when they perceived organizational fairness or had a high level of ethical faith. Lee et al. [58] also observed that employees may unwittingly display the same behaviors, but they were less likely to if they had a high level of moral identity. Meier and Cho [39] said that the higher the positive job satisfaction with social relationships in an organization, the lower the negative impact of social undermining. Shu and Lazatkhan [7] also demonstrated that positive confidence weakens the negative impact of social undermining.

Based on the above studies, we supposed that the negative influence of social undermining on employees' emotional exhaustion and procrastination behaviors decreases when they have adequate PPC. Thus, we assumed that the effects would be felt through the moderating role of PPC, as stated in Hypothesis 4:

Hypothesis 4. Employees' PPC reduces the effect of social undermining on emotional exhaustion and procrastination behavior.

\section{Research Methodology}

\subsection{Sample and Data Collection}

The data used in this study were collected from five 5-star hotels in Seoul, the capital of South Korea, in 2018. The 5-star hotels were defined as those with 200 or more rooms. A total of 22 five-star hotels were selected using the 2017 data from the Korea Tourism Organization. The authors requested participation in a survey from all 22 hotels. Among them, five hotels agreed to take the survey. A total of 100 questionnaires were distributed to each of the five hotels after consent was obtained from their human resource managers. The sample size was determined by population size. Assuming the number of frontline employees of each hotel to be 400 on average and the number of total employees to be approximately 8800 , the number of experimental subjects was 440 with a $5 \%$ margin of error. The sample size was determined to be 500 by considering the effective sample size. Convenience sampling was employed because it was impossible to obtain the consent of each respondent. A total of 500 employees participated in the study by completing a selfadministered questionnaire. Survey participants were able to withdraw from participation at any time, even after the survey was initiated, and they were notified in advance that there would be no disadvantage resulting from such withdrawal. Our explanation of the research purpose was provided in the first part of the questionnaire. The subjects completed the survey questionnaire in a separately prepared place during their designated breaks. The completed questionnaires were put in a sealed envelope to protect anonymity, which we then collected. Incomplete questionnaires were removed, and a total of 310 questionnaires were used for final analysis. The sex ratio was $58.4 \%$ male to $41.6 \%$ female. Most employees $(51.5 \%)$ were 30 to 39 years of age. Employees' education levels were reported as primarily holding a university degree $(46.1 \%)$, and $42.3 \%$ of the sample had been working for 6 to 10 years at the current hotel.

\subsection{Instrument Development}

By referring to Brislin [59], the questionnaire items originally written in English were translated to the Korean language using the reverse-translation method. According to Adler [60], the reverse-translation method should be performed by those who are well-aware of the relevant culture as well as the language. For conceptual homogeneity and accuracy, we corrected ambiguous expressions before administering the survey. The ambiguous expressions were deleted through a pre-test (50 subjects). The confirmed operational definition of the measurement items is described next. Social undermining was measured using the 12-item instrument developed by the scales by Duffy et al. [4]. In addition, emotional exhaustion was evaluated using a 5-item scale developed by Tepper [61] 
and Maslach and Jackson [62]. To measure employees' procrastination behavior, seven items were adopted from the scales developed by Lay [63] and Metin et al. [64]. PPC was evaluated with a 6-item scale developed by Luthans et al. [21] and Luthans and Youssef [65]. All items were rated on a 7 -point Likert scale $(1=$ strongly disagree to $7=$ strongly agree).

\subsection{Data Analysis}

We ascertained the validity and reliability of the measured items and verified the study hypotheses using IBM SPSS ver. 23.0 (IBM, Armonk, NY, USA) and IBM Analysis of a Moment Structures (Amos) ver. 24.0. SPSS was employed to examine the respondents' demographic characteristics and the reliability of the scales and to perform a descriptive statistical analysis. In addition, a second-order confirmatory factor analysis was performed [66] because the first-order structure was reflective and the second-order structure was formative. In particular, this analysis method was chosen to find the three-factor structure if there were multiple sub-dimensions, as in social undermining. Amos was used to verify the validity of measured items, and to analyze structural equation modeling (SEM) aimed at verifying the four hypotheses.

\section{Results}

\subsection{Measurement Model}

The CFA was conducted using the two-step approach of Anderson and Gerbing [67], and a second-order confirmatory factor analysis was performed for a clear inference of the sub-concepts of social undermining. CFA is a method used to analyze the validity of the factor structure of measured variables collected before investigating the causal relationships of a developed theoretical model. Notably, we used higher-order construct models to test the unidimensionality of concepts, and to test the validity of multiple sub-dimensions. First, the adequacy of the measurement models for the three sub-dimensions of social undermining was evaluated based on the results of a comparative analysis. This showed that one second-order factor and three first-order factors were most appropriate (Table 1). Based on this result, a second-order CFA was performed. As shown in Table 2, Cronbach's alpha ranged from 0.718 to 0.966 according to the reliability test, which is acceptable [68]. The composite construct reliability was 0.6 or higher. Path coefficients of all measured items were 0.7 or higher except for the second-order values $[67,69]$. In addition, the overall goodness-of-fit of the model was excellent $\left(\chi^{2}=750.865\right.$; degree of freedom $=396 ; \chi^{2} /$ degree of freedom $=1.896$; comparative fix index $(\mathrm{CFI})=0.854$; normed fit index $(\mathrm{NFI})=0.915$; $\mathrm{CFI}=0.958$; root mean square error of approximation $(\mathrm{RMSEA})=0.054)$. ASV and MSV were smaller than the AVE value; thus, the discriminant validity of the model was proved (Table 3).

Table 1. Comparison of measurement models for social undermining.

\begin{tabular}{cccccccccc}
\hline Model & Factor & $\chi^{2}$ & df & $\Delta \chi^{2}$ & $\chi^{2} / \mathbf{d f}$ & GFI & CFI & RMSEA & AIC \\
\hline 1 & One factor & 1077.754 & 54 & - & 19.958 & 0.554 & 0.658 & 0.235 & 1125.754 \\
2 & Three first-order factors & 404.074 & 54 & - & 7.483 & 0.831 & 0.883 & 0.137 & 452.074 \\
3 & One second-order factor & 163.383 & 51 & $123.30 *$ & 3.204 & 0.926 & 0.962 & 0.080 & 217.383 \\
\hline
\end{tabular}

Note: ${ }^{*} p<0.05\left(\Delta \chi_{\mathrm{df}=3}^{2} 7.81\right)$.

\subsection{SEM}

Table 4 displays the directionality and the influence of the structured path coefficients. The chi-squared value shows that the overall model was not appropriate for the data $\left(\mathrm{df}=246, \chi^{2}=501.555, p<0.001\right)$; as it sensitively responded to the size of the sample [70], other goodness-of-fit indexes were reviewed. The $\chi^{2} / \mathrm{df}, \mathrm{GFI}, \mathrm{NFI}, \mathrm{CFI}, \mathrm{IFI}, \mathrm{RMSEA}$, and RMR were $2.039,0.875,0.920,0.957,0.958,0.058$, and 0.092 , respectively, and the goodnessof-fit of the structural model was verified [71]. 
Table 2. Reliabilities and confirmatory factor analysis properties.

\begin{tabular}{|c|c|c|c|c|}
\hline Construct & Standardized Loading & $t$-Value & $\begin{array}{c}\text { Composite } \\
\text { Reliabilities (AVE) }\end{array}$ & Cronbach's Alpha \\
\hline Supervisor undermining & & & 0.837 & 0.890 \\
\hline $\mathrm{SU}_{1}$ & 0.804 & Fixed & $(0.670)$ & \\
\hline $\mathrm{SU}_{2}$ & 0.792 & $15.212^{* * *}$ & & \\
\hline $\mathrm{SU}_{3}$ & 0.883 & $17.310^{* * *}$ & & \\
\hline $\mathrm{SU}_{4}$ & 0.794 & $15.256^{* * *}$ & & \\
\hline Co-worker undermining & & & 0.849 & 0.904 \\
\hline $\mathrm{SU}_{5}$ & 0.856 & fixed & $(0.703)$ & \\
\hline $\mathrm{SU}_{6}$ & 0.843 & $18.192^{* * *}$ & & \\
\hline $\mathrm{SU}_{7}$ & 0.799 & $16.769^{* * *}$ & & \\
\hline $\mathrm{SU}_{8}$ & 0.857 & $18.636^{* * *}$ & & \\
\hline Customer undermining & & & 0.925 & 0.922 \\
\hline $\mathrm{SU}_{9}$ & 0.862 & fixed & $(0.768)$ & \\
\hline $\mathrm{SU}_{10}$ & 0.893 & $27.214^{* * *}$ & & \\
\hline $\mathrm{SU}_{11}$ & 0.884 & $26.742^{* * *}$ & & \\
\hline $\mathrm{SU}_{12}$ & 0.867 & $25.137^{* * *}$ & & \\
\hline Social undermining & & & 0.621 & 0.718 \\
\hline Supervisor undermining & 0.789 & fixed & $(0.421)$ & \\
\hline Coworker undermining & 0.552 & $6.259^{* * *}$ & & \\
\hline Customer undermining & 0.582 & $6.674^{* * *}$ & & \\
\hline Emotional exhaustion & & & 0.869 & 0.901 \\
\hline $\mathrm{EX}_{1}$ & 0.700 & fixed & $(0.650)$ & \\
\hline $\mathrm{EX}_{2}$ & 0.868 & $13.261^{* * *}$ & & \\
\hline $\mathrm{EX}_{3}$ & 0.808 & $12.523^{* * *}$ & & \\
\hline $\mathrm{EX}_{4}$ & 0.851 & $13.066^{* * *}$ & & \\
\hline $\mathrm{EX}_{5}$ & 0.822 & $12.697^{* * *}$ & & \\
\hline Procrastination behavior & & & 0.899 & 0.948 \\
\hline $\mathrm{PB}_{1}$ & 0.863 & fixed & $(0.723)$ & \\
\hline $\mathrm{PB}_{2}$ & 0.869 & $20.776^{* * *}$ & & \\
\hline $\mathrm{PB}_{3}$ & 0.854 & $20.089^{* * *}$ & & \\
\hline $\mathrm{PB}_{4}$ & 0.784 & $17.303^{* * *}$ & & \\
\hline $\mathrm{PB}_{5}$ & 0.842 & $19.585^{* * *}$ & & \\
\hline $\mathrm{PB}_{6}$ & 0.856 & $20.183^{* * *}$ & & \\
\hline $\mathrm{PB}_{7}$ & 0.883 & $21.427^{* * *}$ & & \\
\hline $\begin{array}{l}\text { Positive psychological } \\
\text { capital }\end{array}$ & & & 0.940 & 0.966 \\
\hline $\mathrm{PPC}_{1}$ & 0.921 & fixed & $(0.826)$ & \\
\hline $\mathrm{PPC}_{2}$ & 0.918 & $28.309 * * *$ & & \\
\hline $\mathrm{PPC}_{3}$ & 0.908 & $27.326^{* * *}$ & & \\
\hline $\mathrm{PPC}_{4}$ & 0.907 & $27.360^{* * *}$ & & \\
\hline $\mathrm{PPC}_{5}$ & 0.900 & $26.669^{* * *}$ & & \\
\hline $\mathrm{PPC}_{6}$ & 0.901 & $26.654^{* * *}$ & & \\
\hline
\end{tabular}

Note: $\chi^{2}=750.864, \mathrm{df}=396, \chi^{2} / \mathrm{df}=1.896$, goodness-of-fit index $(\mathrm{GFI})=0.854$, normed fit index $(\mathrm{NFI})=0.915$ comparative fit index $(\mathrm{CFI})=0.958$, root mean square error of approximation (RMSEA) $=0.054 ;{ }^{* * *} p<0.001$.

Table 3. Mean, standard deviations and correlations among the latent constructs.

\begin{tabular}{ccccccccc}
\hline Construct & \multicolumn{4}{c}{ Discriminant Validity } & \multicolumn{3}{c}{ Descriptive Statistics } \\
\cline { 2 - 9 } & $\mathbf{1}$ & $\mathbf{2}$ & $\mathbf{3}$ & $\mathbf{4}$ & AVE & ASV & MSV & M SD \\
\hline 1. Social undermining & 1 & & & & 0.421 & 0.179 & 0.260 & $4.77 \pm 0.87$ \\
2. Emotional exhaustion & 0.424 & 1 & & & 0.650 & 0.124 & 0.260 & $4.67 \pm 0.99$ \\
3. Procrastination behavior & 0.101 & 0.301 & 1 & & 0.723 & 0.091 & 0.158 & $3.73 \pm 1.24$ \\
4. Positive psychological capital & -0.183 & -0.190 & -0.388 & 1 & 0.826 & 0.062 & 0.158 & $3.85 \pm 1.25$ \\
\hline
\end{tabular}

Note: All correlations are significant at $p=0.05 ; \mathrm{SD}=$ standard deviation; $\mathrm{AVE}=$ average variance extracted, $\mathrm{ASV}=$ average shared variance; $\mathrm{MSV}=$ maximum shared variance. 
Table 4. Structural parameter estimates.

\begin{tabular}{|c|c|c|c|}
\hline Hypothesized Path (Stated as Alternative Hypothesis) & $\begin{array}{l}\text { Standardized Path } \\
\text { Coefficients }\end{array}$ & $t$-Value & Results \\
\hline $\begin{array}{c}\text { Hypothesis 1: Social undermining } \rightarrow \text { Emotional exhaustion } \\
\text { Hypothesis 2: Social undermining } \rightarrow \text { Procrastination behavior } \\
\text { Hypothesis 3: Emotional exhaustion } \rightarrow \text { Procrastination behavior } \\
\text { Goodness-of-fit statistics }\end{array}$ & $\begin{array}{c}0.511 \\
0.068 \\
0.360 \\
\chi^{2}(246)=501.555(p<0.001) \\
\chi^{2} / \mathrm{df}=2.039 \\
\mathrm{GFI}=0.875 \\
\mathrm{NFI}=0.920 \\
\mathrm{CFI}=0.957 \\
\mathrm{IFI}=0.958 \\
\text { RMSEA }=0.058 \\
\text { RMR }=0.092\end{array}$ & $\begin{array}{l}5.669^{* * *} \\
0.810^{\mathrm{ns}} \\
4.605^{* * *}\end{array}$ & $\begin{array}{l}\text { Adopted } \\
\text { Not adopted } \\
\text { Adopted }\end{array}$ \\
\hline
\end{tabular}

Note: ${ }^{* * *} p<0.001,{ }^{\text {ns }}$ not significant; GFI = goodness-of-fit index; NFI = normed fit index; CFI = comparative fit index; IFI = incremental fit index; RMSEA = root mean square error of approximation; RMR = root mean square residual. Fully mediating role of emotional exhaustion. Indirect effect: Social undermining $\rightarrow$ emotional exhaustion $\rightarrow$ procrastination behavior. Point estimate: $0.184(p<0.05)$; bias-corrected bootstrap 95\% CI: 0.125 (LL); 0.270 (UL). Aroian version of the Sobel test: $\mathrm{Z}=2.651(p<0.05)$.

The analysis led to the support of hypothesis 1 , on the positive relationship between social undermining perceived by employees and their emotional exhaustion (beta value $=0.511, t$ value $=5.669, p<0.001$ ). These analysis results indicated that employees who clearly perceived social undermining were likely to experience increased emotional exhaustion. On the other hand, hypothesis 2 , on the positive relationship between social undermining and procrastination behavior, was not supported (beta-Value $=0.068$, $t$-Value $=0.810, p>0.05)$. In this study, social undermining perceived by employees had no direct significant effect on employees' procrastination behavior. As predicted, hypothesis 3 , on the positive influence of employees' emotional exhaustion on their procrastination behavior, was supported (beta value $=0.360$, $t$-value $=4.605, p<0.001$ ). This means that employees were likely to use procrastination behaviors harmful to their organization as their emotional exhaustion increased. The support for hypotheses 1 and 3 means that employees' perceived social undermining indirectly affected their procrastination behaviors via their emotional exhaustion, although their social undermining and procrastination behavior had no direct association with each other. Accordingly, such a causal relationship verified the mediating effect of emotional exhaustion. In the model, the direct effect of emotional exhaustion on procrastination behavior was controlled to be zero to examine the mediating effect of emotional exhaustion. We evaluated whether the four conditions for the mediating role of emotional exhaustion, for which we referred to Baron and Kenny [72], were met (beta value $=0.184, p<0.05$ ). As a result of bootstrapping to confirm the statistical significance of the indirect effect, as mentioned by Preacher and Hayes [73], we found that zero was not included in this section (LL and UL). The Sobel test also showed the importance of emotional exhaustion [74], supporting its fully mediating effect (Z-score $2.651, p<0.05)$, whereby the fully mediating effect of emotional exhaustion being verified was considered.

In addition, to verify hypothesis 4 , of the causal relationship among social undermining, emotional exhaustion, and procrastination behavior being moderated by employees PPC, the unconstrained model and the constrained model were comparatively analyzed (Table 5). We performed the analysis by differentiating the subjects into groups with high and low PPC, based on their average value. The analysis results showed that the positive influence of social undermining on procrastination behavior was significant only when the level of PPC was low and when employees with a high level of PPC did not use procrastination behaviors caused by social undermining. Although there was no significant moderating effect of PPC on the relationship between social undermining and emotional exhaustion or between emotional exhaustion and procrastination behavior, the 
negative influence of social undermining was partially decreased by high PPC. Accordingly, hypothesis 4 was partially supported.

Table 5. Moderating effects of employees' positive psychological capital (PPC).

\begin{tabular}{|c|c|c|c|c|c|c|c|}
\hline & \multicolumn{2}{|c|}{ High PPC $(N=181)$} & \multicolumn{2}{|c|}{ Low PPC $(N=129)$} & \multirow{2}{*}{$\begin{array}{c}\text { Unconstrained } \\
\text { Model Chi-Squared } \\
(\mathrm{df}=492)\end{array}$} & \multirow{2}{*}{$\begin{array}{c}\text { Constrained Model } \\
\text { Chi-Squared } \\
(\mathrm{df}=493)\end{array}$} & \multirow{2}{*}{$\begin{array}{c}\Delta \chi^{2} \\
(\mathrm{df}=1)\end{array}$} \\
\hline & $\begin{array}{l}\text { Standardized } \\
\text { Coefficients }\end{array}$ & $t$-Value & $\begin{array}{l}\text { Standardized } \\
\text { Coefficients }\end{array}$ & $t$-Value & & & \\
\hline $\begin{array}{c}\text { Social undermining } \rightarrow \\
\text { Emotional exhaustion }\end{array}$ & 0.376 & $3.105^{* *}$ & 0.588 & $4.537^{* * *}$ & & 865.011 & $3.981^{\mathrm{ns}}$ \\
\hline $\begin{array}{l}\text { Social undermining } \rightarrow \\
\text { Procrastination behavior }\end{array}$ & 0.173 & $1.686^{\mathrm{ns}}$ & 0.402 & $2.625^{* *}$ & 861.030 & 871.555 & 10.025 * \\
\hline $\begin{array}{l}\text { Emotional exhaustion } \rightarrow \\
\text { Procrastination behavior }\end{array}$ & 0.287 & $3.146^{* *}$ & 0.477 & $3.479^{* * *}$ & & 861.038 & $0.008^{\mathrm{ns}}$ \\
\hline
\end{tabular}

Note: $\chi^{2} / \mathrm{df}=1.750 ; \mathrm{GFI}=0.797 ; \mathrm{NFI}=0.852 ; \mathrm{TLI}=0.930 ; \mathrm{CFI}=0.938 ; \mathrm{IFI}=0.939 ; \mathrm{RMSEA}=0.049 ;{ }^{*} p<0.05$, ${ }^{* *} p<0.01,{ }^{* * *} p<0.001,{ }^{\text {ns }}$ Not significant.

\section{Discussion and Implications}

\subsection{Discussion and Theoretical Implications}

The aim of this study was to examine the influence of social undermining on the emotional exhaustion and the procrastination behavior of deluxe hotel frontline employees and to clarify the moderating role of PPC in this causal relationship. This was prompted by the increasing importance of social undermining experienced by employees during the socialization process in their organizations. The study results showed that social undermining perceived by deluxe hotel employees positively influenced their emotional exhaustion. This is consistent with previous studies that showed that employees' emotional exhaustion became severe when they experienced social undermining in a job situation $[30,31,34]$. In addition, when emotional exhaustion became severe, employees' procrastination behavior that was harmful to their organizations increased; this suggested that the emotional exhaustion they experience in their organizations is likely to lead to a high level of procrastination behavior [53]. On the contrary, a low level of emotional exhaustion decreased procrastination behavior. Nonetheless, a prudent approach is necessary to interpret the analysis results of the insignificant relationship between social undermining and procrastination behavior. The results of the present study are not consistent with those of previous studies that verified the causal relationship between social undermining and employees' negative behaviors [4], and a direct causal relationship between social undermining and employees' procrastination behaviors was not ascertained. In other words, procrastination behaviors may not increase even after experiencing social undermining. Nevertheless, we verified the mediating effect, indicating that employees' procrastination behaviors may increase when they experience emotional exhaustion resulting from social undermining. The findings of Ong and Tray [46] support the results of this study, showing that there is no direct correlation between social undermining and employees' counterproductive behaviors. Another study concluded that employees with a high level of PPC were relatively less likely to use procrastination behaviors resulting from social undermining than those with a low level of PPC [21]. This means that when employees perform their job with a positive attitude in a work situation, the negative influence of social undermining and emotional exhaustion may be partially offset.

Based on these results, theoretical implications of this study can be summarized as follows: The subject of this study was employees performing services in the forefront of deluxe hotels. In case of the deluxe hotel employees who work through regular interaction with bosses and colleagues in a restricted space of hotel, the occurrence frequency of social undermining is likely to be higher than for other jobs. From this perspective, this study's findings have academic significance as this was a pioneering work in which we examined the extent of social undermining that prevails in deluxe hotels. Furthermore, most of the previous studies related to the social undermining were single-dimensional research that examined the differences in awareness at an exploratory level. In our study, in which 
we examined social undermining from multiple perspectives through second-order factor analysis, provides fundamental data necessary for stimulating or expanding future studies.

\subsection{Practical Implications}

We suggest the following points: Through this study, we attempted to call the attention of managers of 5-star hotels to the importance of social undermining by highlighting its negative effect on organizational performance. One important finding of this study is that, thus far, many studies have examined the significant association between social undermining and employees' negative behaviors, but no research had been conducted on deluxe hotel employees. In addition, a scarcely considered dependent variable, procrastination behavior as a negative behavior, was employed for this study. Clearly, social undermining does not directly contribute to increasing employees' procrastination behaviors. Nonetheless, this study's findings clarified the organic mechanism that may encourage employees' procrastination behaviors as social undermining perceived by them during the socialization process increases employees' emotional exhaustion. This study has practical meaning: organizations can encourage members to progressively respond to disadvantageous social undermining. They should encourage their members to control and manage negative emotions in an appropriate way. Furthermore, this study verified that the negative influence of social undermining may be alleviated by a high level of PPC, which is an intangible resource and not a fixed character that may be changed by the employees' organizations, coworkers, and supervisors. We explored a new variable that may moderate the causal relationship rather than simply verifying it. Specific measures to equip employees with a high level of PPC are needed to weaken the influence of social undermining. Among others, establishing a supportive organizational culture and atmosphere by providing diverse learning opportunities and psychological counseling is necessary to understand organizational members' psychological conditions. Moreover, supporting activities other than work tasks, such as leisure programs after work or small group meetings within the company, is necessary so that employees can share positive emotions with their coworkers and superiors. Another implication of this study is that the importance of social undermining should be recognized and that attention should be paid to it. The perpetrators of social undermining that occurs in an organization may be unaware that they are harming others; therefore, education using visual data or videos should be provided that publicize socially undermining behaviors. In addition, we verified that the role of a manager is important in creating an ethical atmosphere so that social undermining does not take place. Management should be aware of the ripple effect of social undermining and should make it known that it is a significantly negative and harmful behavior that employees should avoid. From a long-term perspective, a systematic tool to prevent social undermining should be developed. To this end, an organizational cultural atmosphere should be established in which members do not denounce or undermine others during the socialization process. In particular, it should be emphasized that such behaviors may affect individual employees' performance and their organization's morale, and may disturb the organization's goals. An organizational culture in which social undermining is prevalent is directly related to the ethical image of the organization, and the resulting ripple effect is considerable. Therefore, improvement in the communication system at an organizational level or the formation of an autonomous organizational atmosphere is necessary.

\subsection{Limitations and Future Research}

First, the sample of this study was confined to frontline employees in deluxe hotels, and generalization of the results should be applied to the specific scope of this industry. Moreover, the respondents participated in the survey based on their own free will, but their managers encouraged their participation, which may have influenced their responses. Second, this study emphasized the importance of social undermining but did not determine a direct effect of social undermining perceived by employees on their procrastination behaviors. Therefore, future research should explore and evaluate a new variable that 
mediates or moderates social undermining and procrastination behaviors. Furthermore, individual variables, such as sensitivity to ethical values, sex, or cultural differences that may weaken the relationships among the elements should be taken into consideration. For example, research is necessary on whether employees in an Asian culture more frequently experience social undermining than their counterparts in a Western culture and whether the negative influence of social undermining on the former is stronger than that on the latter. Third, in this study, social undermining perceived by hotel employees in deluxe hotels was examined experientially. Such research results provide valuable insights into the associations among social undermining, emotional exhaustion, procrastination behavior, and PPC. In future research, the scope of the subjects should be expanded to include customers, superiors, coworkers, and managers to reduce social undermining by employees given the dynamics of the deluxe hotel industry.

Author Contributions: The authors contributed equally to this work. Conceptualization, H.-S.J. and H.-H.Y.; methodology, H.-S.J. and H.-H.Y.; software, H.-S.J.; validation, H.-S.J. and H.-H.Y.; formal analysis, H.-S.J.; Investigation and data curation, H.-S.J. and H.-H.Y.; writing-original draft preparation, H.-S.J. and H.-H.Y.; writing—review and editing, H.-S.J. and H.-H.Y. All authors have read and agreed to the published version of the manuscript.

Funding: For Hyo-Sun Jung, this work was supported by a grant from Kyung Hee University in 2021 (KHU-20210161).

Institutional Review Board Statement: Not applicable.

Informed Consent Statement: Not applicable.

Data Availability Statement: The data presented in this study are available on request from the first author.

Conflicts of Interest: The authors declare no conflict of interest.

\section{References}

1. Olson-Buchanan, J.B.; Boswell, W.R. Mistreatment in the Workplace. Prevention and Resolution for Managers and Organizations; Wiley-Blackwell: Chichester, UK, 2009.

2. Sârbescu, P.; Sulea, C.; Moza, D. Supervisor undermining and driving errors in truck drivers: A moderated mediation model. Transp. Res. Part F Traffic Psychol. Behav. 2017, 45, 122-130. [CrossRef]

3. Eissa, G.; Wyland, R.; Gupta, R. Supervisor to coworker social undermining: The moderating roles of bottom-line mentality and self-efficacy. J. Manag. Organ. 2020, 26, 756-773. [CrossRef]

4. Duffy, M.K.; Ganster, D.C.; Pagon, M. Social undermining in the workplace. Acad. Manag. J. 2002, 45, 331-351.

5. Kim, H.Y.; Wiesenfeld, B.M. Who represents our group? The effects of prototype content on perceived status dispersion and social undermining. Pers. Soc. Psychol. Bull. 2017, 43, 814-827. [CrossRef]

6. Keeves, G.D.; Westphal, J.D.; McDonald, M.L. Those closest wield the sharpest knife: How ingratiation leads to resentment and social undermining of the CEO. Adm. Sci. Q. 2017, 62, 484-523. [CrossRef]

7. Shu, C.Y.; Lazatkhan, J. Effect of leader-member exchange on employee envy and work behavior moderated by self-esteem and neuroticiam. J. Work Organ. Psychol. 2017, 22, 69-81.

8. Quade, M.J.; Greenbaum, R.L.; Mawritz, M.B. If only my coworker was more ethical: When ethical and performance comparisons lead to negative emotions, social undermining, and ostracism. J. Bus. Ethics 2019, 159, 567-586. [CrossRef]

9. Duffy, M.K.; Scott, K.L.; Shaw, J.D.; Tepper, B.J.; Aquino, K. A social context model of envy and social undermining. Acad. Manag. J. 2012, 55, 643-666. [CrossRef]

10. Anwar, F.; Sidin, J.P. Social undermining, stress and well-being: A mediation Mechanism. Int. J. Bus. Econ. Aff. $2016,1,86-92$.

11. Finch, J.F. Social undermining, support satisfaction, and affect: A domain-specific lagged effects model. J. Pers. 1998, 66, 315-333. [CrossRef]

12. Greenbaum, R.; Mawritz, M.B.; Eissa, G. Bottom-Line mentality as an antecedent of social undermining and the moderating roles of core self-evaluations and conscientiousness. J. Appl. Psychol. 2012, 97, 343-359. [CrossRef] [PubMed]

13. Mathisen, G.E.; Einarsen, S.; Mykletun, R. The occurrences and correlates of bullying and harassment in the restaurant sector. Scandinavian. J. Psychol. 2008, 49, 59-68. [CrossRef]

14. Crossley, C.D. Emotional and behavioral reactions to social undermining: A closer look at perceived offender motives. Organ. Behav. Hum. Decis. Process 2009, 108, 14-24. [CrossRef]

15. Nguyen, B.; Steel, P.; Ferrari, J.R. Procrastination's impact in the workplace and the workplace's impact on procrastination. Int. J. Sel. Assess. 2013, 21, 388-399. [CrossRef] 
16. Ferrari, J.R.; Doroszko, E.; Joseph, N. Exploring procrastination in corporate settings: Sex, status, and settings for arousal and avoidance types. Individ. Differ. Res. 2005, 3, 140-149.

17. Sirois, F.M. Procrastination and stress: Exploring the role of self-compassion. Self Identity 2014, 13, 128-145. [CrossRef]

18. Sharma, B.R.; Gupta, M. Gender based violence in India: A never-ending phenomenon. J. Int. Womens's Stud. 2004, 6, 114-123.

19. Chen, K.Y.; Chang, C.W.; Wang, C.H. Frontline employees' passion and emotional exhaustion: The mediating role of emotional labor strategies. Int. J. Hosp. Manag. 2019, 76, 163-172. [CrossRef]

20. Luthans, F.; Avolio, B.J.; Walumbwa, F.O.; Li, W. The psychological capital of Chinese workers: Exploring the relationship with performance. Manag. Organ. Rev. 2005, 1, 249-271. [CrossRef]

21. Luthans, F.; Vogelgesang, G.R.; Lester, P.B. Developing the psychological capital of resiliency. Hum. Res. Dev. Rev. 2006, 5, 25-44. [CrossRef]

22. Bandura, A. Social cognitive theory of mass communication. Media Psychol. 2001, 3, 265-299. [CrossRef]

23. Sassali, M. Burn-Out in the Social Services: A Literature Review; Human Services Consultants: Dekal, IL, USA, 1979.

24. Montgomery, A.J.; Panagopolou, E.; Wildt, M.; Meenks, E. Work-family interference emotional labor and burnout. J. Manag. Psychol. 2006, 21, 36-51. [CrossRef]

25. Pines, A.; Aronson, E. Career Burnout: Causes and Cures; Free Press: New York, NY, USA, 1988.

26. Haghbin, M.; McCaffrey, A.; Pychyl, T.A. The complexity of the relation between fear of failure and procrastination. J. Ration. Emot. Cogn. Behav. Ther. 2012, 30, 249-263. [CrossRef]

27. Hobfoll, S.E. Conservation of resources: A new attempt at conceptualizing stress. Am. Psychol. 1989, 44, 513-524. [CrossRef]

28. Wright, T.A.; Hobfoll, S.E. Commitment, psychological well-being and job performance: An examination of conservation of resources (COR) theory and job burnout. J. Bus. Manag. 2004, 9, 389-406.

29. Halbesleben, J.R.B.; Neveu, J.P.; Underdahl, S.C.P.; Westman, M. Getting to the "Cor": Understanding the role of resources in conservation of resources theory. J. Manag. 2014, 40, 1334-1364. [CrossRef]

30. Grant, L.M.; Nagda, B.A.; Brabson, H.V.; Jayaratne, S.; Chess, W.A.; Singh, A. Effects of social support and undermining on African American workers' perceptions of coworker and supervisor relationships and psychological well-being. Soc. Work 1993, $38,158-164$.

31. Andersson, L.M.; Pearson, C.M. Tit for tat? The spiraling effect of incivility in the workplace. Acad. Manag. Rev. 1999, 24, 452-471. [CrossRef]

32. Bakker, A.B.; Demerouti, E.; Dollard, M.G. How job demands affect partners' experience of exhaustion: Integrating work-family conflict and crossover theory. J. Appl. Psychol. 2008, 93, 901-911. [CrossRef] [PubMed]

33. Strongman, L. The psychology of social undermining in organizational behavior. Australas. J. Organ. Psychol. 2016, 6, 1-7.

34. Rahimnia, F.; Sadeghian, S.; Yazdani, P. The moderating role of self-esteem between burnout and social undermining in the nurses of Charity Hospitals in Mashhad. Iran. J. Nurs. 2017, 30, 67-79. [CrossRef]

35. Sulea, C.; Filipescu, R.; Horga, A.; Orţan, C.; Fischmann, R. Interpersonal mistreatment at work and burnout among teachers. Cogn. Brain Behav. Interdiscip. J. 2012, 16, 553-570.

36. Kalliath, J.; Beck, A. Is the path to burnout and turnover paved by a lack of supervisory support? A structural equations test. N. Z. J. Psychol. 2001, 30, 72-78.

37. Muhammad, A.H.; Hamdy, I. Burnout, supervisory support, and work outcomes: A study from an Arabic cultural perspective. Int. J. Commer. Manag. 2005, 15, 230-243. [CrossRef]

38. Charoensukmongkol, P.; Moqbel, M.; Gutierrez-Wirsching, I.S. The role of co-worker and supervisor support on job burnout and job satisfaction. J. Advert. Manag. Res. 2016, 13, 4-22.

39. Meier, L.L.; Cho, E. Work stressors and partner social undermining: Comparing negative affect and psychological detachment as mechanisms. J. Occup. Health Psychol. 2019, 24, 359-372. [CrossRef] [PubMed]

40. Cho, M.; Bonn, M.A.; Han, S.J.; Lee, K.H. Workplace incivility and its effect upon restaurant frontline service employee emotions and service performance. Int. J. Contemp. Hosp. Manag. 2016, 28, 2888-2912. [CrossRef]

41. Prof, H.B.; Yagil, D. The relationship between empowerment, aggressive behaviours of customers, coping, and burnout. Euro. J. Work Organ. Psychol. 2005, 14, 81-99.

42. Sliter, M.; Jex, S.; Wolford, K.; Melnnerney, J. How rude! Emotional labor as a mediator between customer incivility and employee outcomes. J. Occup. Health Psychol. 2010, 15, 468-481. [CrossRef]

43. Duffy, M.K.; Ganster, D.C.; Shaw, J.D.; Johnson, J.L.; Pagon, M. The social context of undermining behavior at work. Organ. Behav. Hum. Decis. Process. 2006, 101, 105-126. [CrossRef]

44. Lee, B.V.; Spector, P.E. The social stressors-counterproductive work behaviors link: Are conflicts with supervisors and coworkers the same? J. Occup. Health Psychol. 2006, 11, 145-156.

45. Yoo, J. The influence of social undermining on the service employee's customer-oriented boundary-spanning behavior. J. Serv. Mark. 2013, 27, 539-550. [CrossRef]

46. Ong, L.D.; Tay, A. The Effects of Co-Workers' Social Undermining Behavior on Employees' Work Behaviours. In Proceedings of the GAI Istanbul International Academic Conference Proceedings, Istanbul, Turkey, 7-10 June 2015.

47. Sabeen, Z.; Arshad, F. Social undermining in academia: Experiences and effects. J. Appl. Res. High. Educ. 2019, 11, 653-663. [CrossRef] 
48. Liang, S.C.; Hsieh, A.T. Burnout and workplace deviance among flight attendants in Taiwan. Psychol. Rep. 2007, 101, 457-468. [CrossRef]

49. Krischer, M.M.; Penney, L.M.; Hunter, E.M. Can counterproductive work behaviors be productive? CWB as emotion-focused coping. J. Occup. Health Psychol. 2010, 15, 154-166. [CrossRef]

50. Cropanzano, R.; Byrne, Z.S.; Bobocel, D.R.; Rupp, D.E. Moral virtues, fairness heuristic, social entities, and other denizens of organizational justice. J. Vocat. Behav. 2001, 58, 164-209. [CrossRef]

51. Van Jaarsveld, D.D.; Walker, D.D.; Skarlicki, D.P. The role of job demands and emotional exhaustion in the relationship between customer and employee incivility. J. Manag. 2010, 36, 1486-1504. [CrossRef]

52. Çelik, M.; Turunc, O; Begenirbas, M. The role of organizational trust, burnout and interpersonal deviance for achieving organizational performance. Int. J. Bus. Manag. Stud. 2011, 3, 179-189.

53. Balkis, M. The relationship between academic procrastination and students' burnout. Hacet. Üniversitesi Ĕ̆itim Fakültesi Derg. 2013, 28, 68-78.

54. Ugwu, L.I.; Enweruzor, I.; Fimber, U.S.; Ugwu, D.I. Nurses' burnout and counterproductive work behavior in a Nigerian sample: The moderating role of emotional intelligence. Int. J. Afr. Nurs. Sci. 2017, 7, 106-113. [CrossRef]

55. Romeo, E.J.; Cruthirds, K.W. The use of humor in the workplace. Acad. Manag. Persp. 2006, 60, 63-64.

56. Lee, D.S.; Choi, Y.D. A study on antecedents and consequences of positive psychological capital on organizations. Korean Manag. Rev. 2010, 39, 1-28.

57. George, J.M.; Brief, A.P. Feeling good-doing good: A conceptual analysis of the mood at work-organizational spontaneity relationship. Psychol. Bull. 1992, 112, 310-329. [CrossRef]

58. Lee, K.; Kim, E.; Bhave, D.P.; Duffy, M.K. Why victims of undermining at work become perpetrators of undermining: An integrative model. J. Appl. Psychol. 2016, 101, 915-924. [CrossRef] [PubMed]

59. Brislin, R.W. Translation and content analysis of oral and written materials. In Handbook of Cross-Cultural Psychology; Triandis, H.C., Lonner, W., Eds.; Allyn and Bacon: Boston, MA, USA, 1980; Volume 2, pp. 389-444.

60. Alder, N. Cross-cultural management research: The ostrich and the trend. Acad. Manag. Rev. 1983, 8, $226-232$.

61. Tepper, B.J. Consequences of abusive supervision. Acad. Manag. J. 2000, 43, 178-190.

62. Maslach, C.; Jackson, S. The measurement of experienced burnout. J. Organ. Behav. 1981, 9, 99-113. [CrossRef]

63. Lay, C. At last, my research article on procrastination. J. Res. Pers. 1986, 20, 474-495. [CrossRef]

64. Metin, U.B.; Taris, T.W.; Peeters, M.C.W. Measuring procrastination at work and its associated workplace aspect. Pers. Individ. Differ. 2016, 101, 254-263. [CrossRef]

65. Luthans, F.; Youssef, C.M. Emerging positive organizational behavior. J. Manag. 2007, 33, 321-349. [CrossRef]

66. Rindskopf, D.M.; Rose, T. Some theory and applications of confirmatory second-order factor analysis. Multivar. Behav. Res. 1988, 23, 51-67. [CrossRef] [PubMed]

67. Anderson, J.C.; Gerbing, D.W. Structural equation modeling in practice: A review and recommended two-step approach. Psychol. Bull. 1988, 103, 411-423. [CrossRef]

68. Nunnally, J. Psychometric Theory, 2nd ed.; McGraw-Hill: New York, NY, USA, 1978.

69. Fornell, C.; Larcker, D.F. Evaluating structural equation models with unobservable variables and measurement error. J. Mark. Res. 1981, 18, 39-50. [CrossRef]

70. Bentler, P.M.; Bonett, D.G. Significance tests and goodness of fit in the analysis of covariance structures. Psychol. Bull. 1980, 8 , 588-606. [CrossRef]

71. Hair, J.; Black, W.C.; Babin, B.J.; Anderson, R.E. Multivariate Data Analysis, 7th ed.; Prentice-Hall: Englewood Cliffs, NJ, USA, 2010.

72. Baron, R.M.; Kenny, D.A. The moderator-mediator variable distinction in social psychological research: Conceptual, strategic, and statistical considerations. J. Pers. Soc. Psychol. 1986, 51, 1173-1182. [CrossRef]

73. Preacher, K.J.; Hayes, A.F. SPSS and SAS procedures for estimating indirect effects in simple mediation models. Behav. Res. Meth. Instrum. Comput. 2004, 36, 717-731. [CrossRef]

74. Sobel, M.E. Asymptotic confidence intervals for indirect effects in structural equation models. Sociol. Methodol. 1982, 13, 290-312. [CrossRef] 